\title{
A STUDY ON CORRELATION BETWEEN HBA1C LEVELS WITH TSH LEVELS IN PATIENTS WITH HYPOTHYROIDISM AND TYPE 2 DIABETES MELLITUS
}

Natarajan Kandasamy1, Thilakavathi Rajendran², Dilip Harindran Vallathol3, Vijayanand Radhakrishnan4, Archana Balakrishnan Mani5, Vijayalakshmi Gurusamy6, Ramya Devi Annamalai ${ }^{7}$, Ayyappan Ganesan ${ }^{8}$

${ }_{1}^{1}$ Professor, Department of Medicine, Government Stanley Medical College, Chennai.

${ }^{2}$ Assistant Professor, Department of Medicine, Government Stanley Medical College, Chennai.

${ }^{3}$ Senior Resident, Department of Medicine, Government Stanley Medical College, Chennai.

${ }^{4}$ Assistant Professor, Department of Medicine, Government Stanley Medical College, Chennai.

${ }^{5}$ Post Graduate, Department of Medicine, Government Stanley Medical College, Chennai.

${ }^{6}$ Post Graduate, Department of Medicine, Government Stanley Medical College, Chennai.

7Post Graduate, Department of Medicine, Government Stanley Medical College, Chennai.

${ }^{8}$ Post Graduate, Department of Medicine, Government Stanley Medical College, Chennai.

ABSTRACT
BACKGROUND
Diabetes and hypothyroidism are two common metabolic disorders that are interrelated. The hallmarks of hypothyroidism are
decreased absorption of glucose from the intestinal tract along with increased accumulation of glucose in the periphery with
decreased glucose production from the liver and decreased use of glucose. For those who have subclinical or overt hypothyroidism,
insulin resistance causes glucose stimulated increase in insulin secretion. Moreover, those with subclinical hypothyroidism have an
independent risk for insulin resistance, especially in the muscle and adipose tissue. Hence, there is a definite link between
hyperinsulinaemia, resistance to insulin and subclinical hypothyroidism.

\section{AIMS AND OBJECTIVES}

To study the correlation between HbA1c and TSH values in Diabetic patients known to have Hypothyroidism.

\section{MATERIALS AND METHODS}

Patients presenting with history of type 2 diabetes mellitus with or without history of hypothyroidism for more than 3 years duration and patients known to have Diabetes who were also on treatment for hypothyroidism presenting to OPDs or admitted in wards from February 2014 to September 2014 were included in the study. Patients were subjected to symptom analysis, clinical examination, blood investigations including HbA1c and TSH levels. Diabetic patients who were newly diagnosed to have hypothyroidism were treated with thyroxine for three months and were followed up with TSH and HbA1c levels measured.

\section{RESULTS}

The study revealed that fasting HbA1c values among Hypothyroid patients were higher when compared to that of euthyroid patients. The study also concluded that the HbA1c values came down after thyroxine supplementation for 3 months in hypothyroid patients.

\section{CONCLUSION}

Measuring TSH in all diabetic patients will help us to find out more number of subclinical hypothyroid patients. Treatment of concomitant hypothyroidism in diabetic patients helps us to achieve better sugar control in them.

\section{KEYWORDS}

Hypothyroidism, Diabetes Mellitus, HbA1c, TSH.

HOW TO CITE THIS ARTICLE: Kandasamy N, Rajendran T, Vallathol DH, et al. A study on correlation between HbA1c levels with TSH levels in patients with hypothyroidism and type 2 diabetes mellitus. J. Evolution Med. Dent. Sci. 2016;5(54):3645-3652, DOI: $10.14260 /$ jemds/2016/840

\section{INTRODUCTION}

Diabetes and hypothyroidism are interrelated metabolic disorders. There is a strong association between thyroid disease and type 2 diabetes, and there are vital consequences for it on insulin sensitivity and treatment.

\section{Financial or Other, Competing Interest: None}

Submission 25-05-2016, Peer Review 18-06-2016,

Acceptance 25-06-2016, Published 07-07-2016.

Corresponding Author:

Dr. Thilakavathi Rajendran,

D4-Baba Nagar,

Mogappair West,

Chennai-37.

E-mail: thilakavathirajendran@gmail.com

DOI: $10.14260 /$ jemds/2016/840
The basis of this is a complex interplay of major signal pathways and associated genetic susceptibility.

There are many literature reviews that have shown a more than normal prevalence of thyroid disorders in type 2 diabetic patients. More commonly hypothyroidism, especially subclinical hypothyroidism is the one most commonly associated with diabetes. The overall prevalence of Thyroid disease in diabetes accounts for up to $10.8 \%$. In that Hypothyroidism accounts for up to $36 \%$, Subclinical hypothyroidism accounts for up to $51 \%$ and Hyperthyroidism accounts for up to $12 \%$. In liver, skeletal muscle and adipose tissue the thyroid hormones have different modes of action and these are the main targets of action.

Their action is opposite to that of insulin in the liver and increases gluconeogenesis and glycogenolysis. 
On the contrary, their action is similar to that of insulin in skeletal muscle and adipose tissue. Thyroid hormone act by up-regulating the expression of GLUT-4 and phosphoglycerate kinase genes, thus facilitating their action along with insulin and improving the disposal and utilisation of sugar in tissues.

For those who have subclinical or overt hypothyroidism, insulin resistance causes glucose stimulated increase in insulin secretion. Moreover, patients with subclinical hypothyroidism have an independent risk for insulin resistance, especially in the muscle and adipose tissue. Hence, there is a definite link between hyperinsulinaemia, resistance to insulin and subclinical hypothyroidism. There are numerous mechanisms through which subclinical hypothyroidism and insulin resistance causes derangement of glycaemic control. Thus, the significance of treating subclinical hypothyroid patients with levothyroxine for better glycaemic control is well understood. Some studies have also shown positive effect of metformin therapy in control of thyroid disorders. At the same time, poorly controlled diabetes further complicates the diagnosis of hypothyroidism by producing changes in thyroid function tests. The alterations include a reduced $\mathrm{T} 3$ due to changes in extrathyroidal T4 to T3 conversion, a decreased level of T4 due to decrease in protein binding and associated low levels of TSH in blood.

\section{AIMS AND OBJECTIVES}

The main objective of this study was to establish correlation between HbA1c and TSH levels in patients who had clinical or subclinical hypothyroidism and type 2 Diabetes Mellitus.

\section{MATERIALS AND METHODS}

This study was carried out in general medicine OPDs, wards and endocrinology OPDs over a period of 10 months after obtaining due Institutional Ethical Committee approval. We included patients who were diabetic for three years with or without history of hypothyroidism and patients with hypothyroidism who were on treatment for diabetes in our study. The study design was a prospective observational study with a sample size of 50 . Patients with diabetes of less than 3 years' duration, patients who presented with hyperglycaemic emergencies or patients with history of thyroid surgeries were excluded from the study. This included patients were subjected to detailed history taking, complete physical examination and the relevant laboratory investigations as per a proforma, exclusively designed for the study. The details of the thyroid problem and diabetes mellitus were obtained from the patients and attenders and scrutinising their old records closely. Patients were tested for diabetes by fasting blood sugar and HbA1c and with TSH levels for hypothyroidism. The HbA1c and TSH were measured before and after administration of levothyroxine separated by a gap of 3 months and their levels were correlated.

\section{STATISTICAL ANALYSIS AND RESULTS}

Descriptive statistics was done for all data and suitable statistical tests of comparison were done. Continuous variables were analysed with the Unpaired ' $t$ ' test and categorical variables were analysed with the Chi-Square Test and Fisher Exact Test. Statistical significance was taken as $\mathrm{P}<0.05$. The data was analysed using EpiInfo software (7.1.0.6 version; Center for disease control, USA) and Microsoft Excel 2010.

\section{SAMPLE SIZE CALCULATION}

Sample size was determined on the basis of a pilot study in which the prevalence of hypothyroidism in diabetes mellitus was measured at $15 \%$. We calculated a minimum sample size of 48 patients was required in each group, assuming a type 1 error (Two-tailed) of 0.05 and a margin of error of $10 \%$. Therefore, the final sample selected was $n=50$.

$$
\mathrm{n}=\frac{\mathrm{t}^{2} \times \mathrm{p}(1-\mathrm{p})}{\mathrm{m}^{2}}
$$

\section{Description}

$\mathrm{n}=$ Required sample size.

$\mathrm{t}=$ Confidence level at 95\% (Standard value of 1.96).

$\mathrm{p}=$ Estimated prevalence of malnutrition in the project area (15\%).

$\mathrm{m}=$ Margin of error at $10 \%$ (Standard value of 0.05 ).

$$
\begin{aligned}
\mathrm{N} & =\frac{(1.96)^{2} \times 0.15(1-0.15)}{(0.01)^{2}} \\
\mathrm{~N} & =\frac{3.8146 \times 0.1275}{0.0001} \\
& =
\end{aligned}
$$

\begin{tabular}{|c|c|c|c|}
\hline $\begin{array}{c}\text { Treatment } \\
\text { Groups }\end{array}$ & $\begin{array}{c}\text { Name of } \\
\text { Group }\end{array}$ & Study & $\begin{array}{c}\text { Number } \\
\text { of } \\
\text { Subjects }\end{array}$ \\
\hline Group A & Euthyroid & $\begin{array}{c}\text { To assess the } \\
\text { prevalence of } \\
\text { hypothyroidism } \\
\text { in diabetes } \\
\text { mellitus }\end{array}$ & 45 \\
\hline \multicolumn{3}{|c|}{ Table 1: Table showing the Group Distribution } \\
of Study Population \\
\hline
\end{tabular}

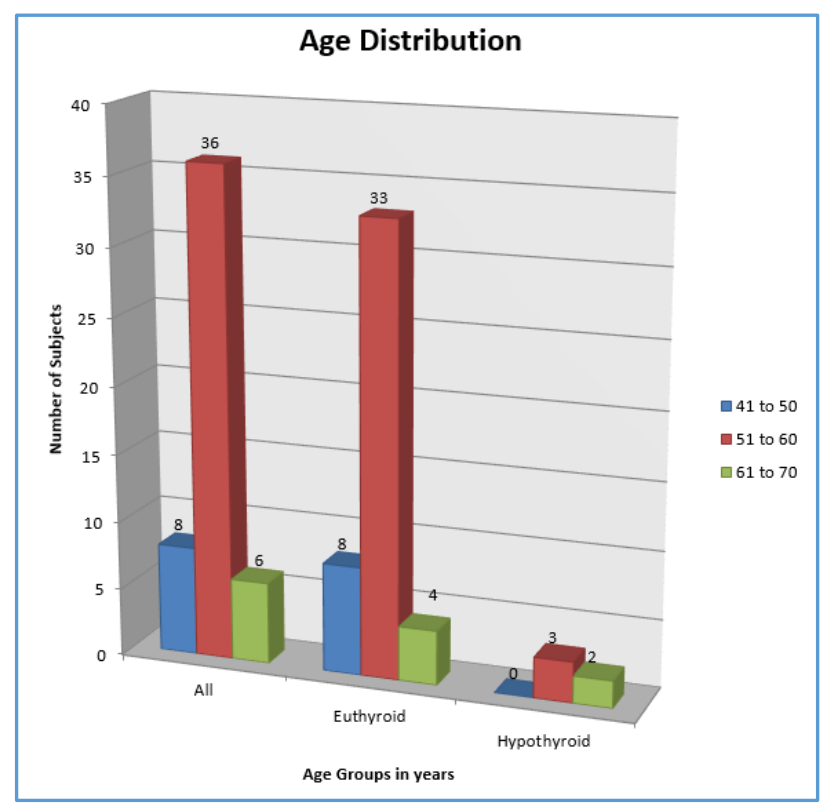

Fig. 1: Bar Diagram showing Age Distribution among Study Population 


\begin{tabular}{|c|c|c|c|c|c|c|}
\hline $\begin{array}{c}\text { Age } \\
\text { Distribution }\end{array}$ & All & $\%$ & 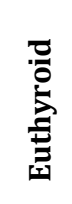 & $\%$ & 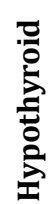 & $\%$ \\
\hline 41 to 50 & 8 & 16 & 8 & 17.77778 & 0 & 0 \\
\hline 51 to 60 & 36 & 72 & 33 & 73.33333 & 3 & 60 \\
\hline 61 to 70 & 6 & 12 & 4 & 8.888889 & 2 & 40 \\
\hline Total & 50 & 100 & 45 & 100 & 5 & 100 \\
\hline
\end{tabular}

\begin{tabular}{|c|c|c|}
\hline Age Distribution & Euthyroid & Hypothyroid \\
\hline N & 45 & 5 \\
\hline Mean & 55.27 & 59.00 \\
\hline SD & 4.43 & 6.75 \\
\hline P value Unpaired 't' test & \multicolumn{2}{|c|}{0.2877207} \\
\hline \multicolumn{2}{|c|}{ Table 3: Statistics of Age Distribution in } \\
Euthyroid and Hypothyroid Group \\
\hline
\end{tabular}

By conventional criteria, the association between the study groups and age is considered to be not statistically significant since $\mathrm{p}>0.05$.

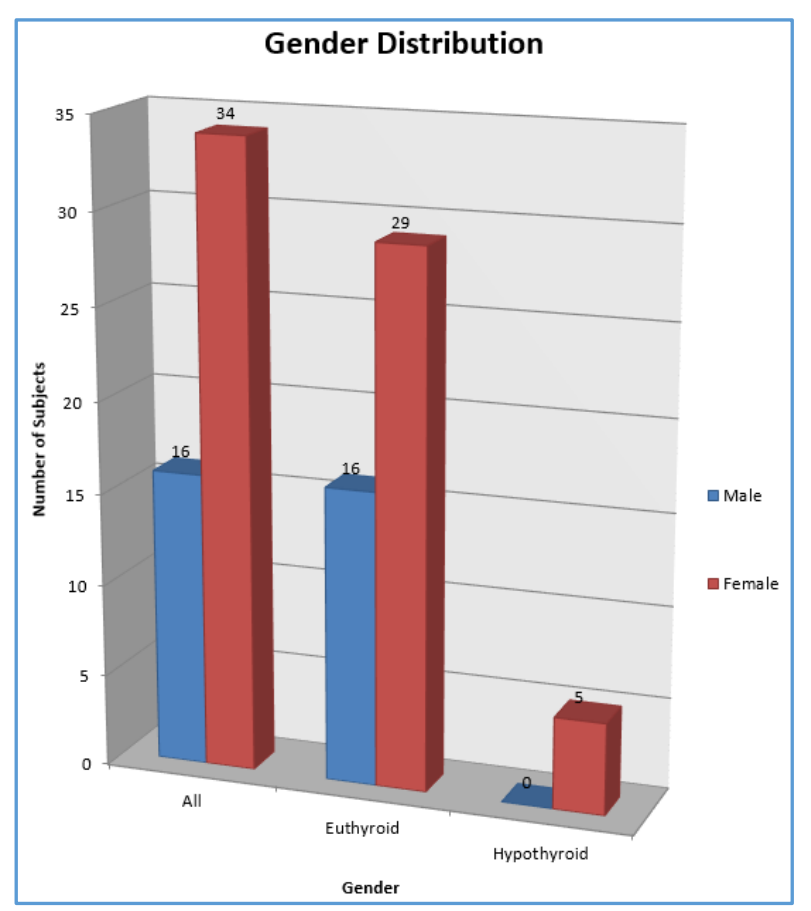

Fig. 2: Bar Diagram showing Gender Distribution among Study Population

\begin{tabular}{|c|c|c|c|c|c|c|}
\hline Gender Distribution & All & $\%$ & & $\%$ & 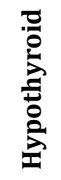 & $\%$ \\
\hline Male & 16 & 32 & 16 & 35.56 & 0 & 0 \\
\hline Female & 34 & 68 & 29 & 64.44 & 5 & 100 \\
\hline Total & 50 & 100 & 45 & 100 & 5 & 100 \\
\hline Chi-square statistic & \multicolumn{6}{|c|}{2.61} \\
\hline Degrees of freedom & \multicolumn{6}{|c|}{1} \\
\hline $\begin{array}{c}\text { P value } \\
\text { Chi squared Test } \\
\text { without Yates } \\
\text { Correction }\end{array}$ & \multicolumn{6}{|c|}{0.106} \\
\hline $\begin{array}{r}\text { Table 4: Statistics o } \\
\text { a }\end{array}$ & . & $\begin{array}{l}\text { Dist } \\
\text { thyro }\end{array}$ & $G r$ & $\begin{array}{l}\text { ame } \\
p\end{array}$ & & vroic \\
\hline
\end{tabular}

By conventional criteria, the association between the study groups and gender is considered to be not statistically significant since $\mathrm{p}>0.05$.

Since age and gender is not statistically significant, it means that there is no difference between the groups. In other words the groups contain subjects with the same basic demographic characteristics.

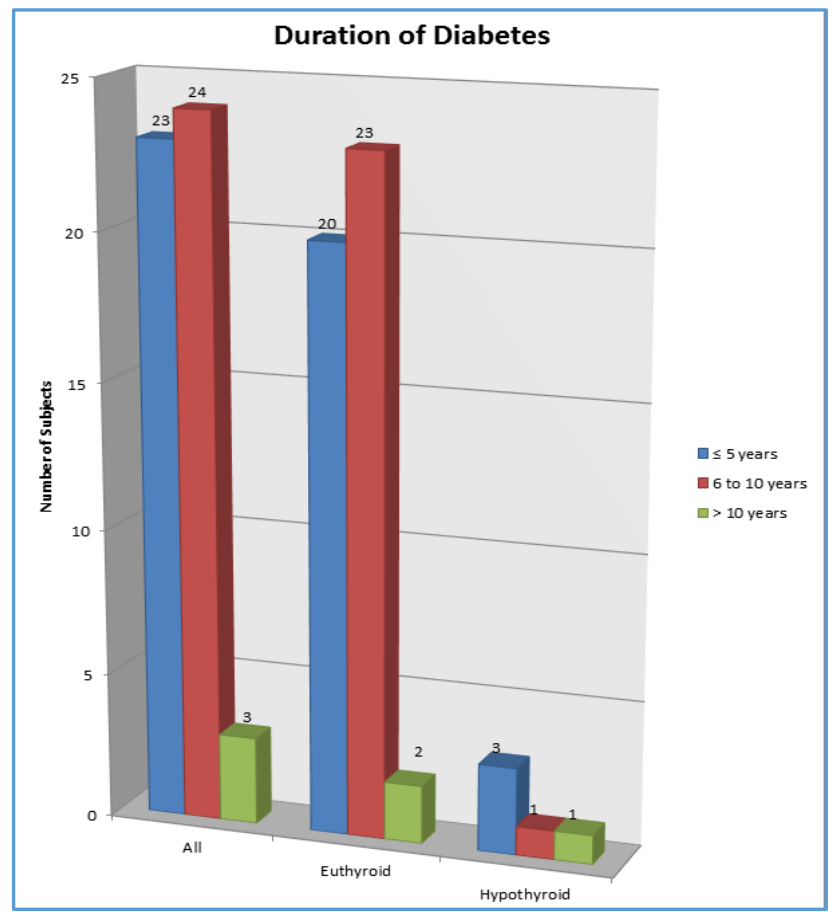

Fig. 3: Bar Diagram Depicting the Duration of Diabetes among Study Population

\begin{tabular}{|c|c|c|c|c|c|c|}
\hline $\begin{array}{c}\text { Duration of } \\
\text { DM }\end{array}$ & All & $\%$ & 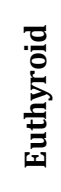 & $\%$ & 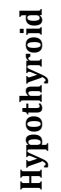 & $\%$ \\
\hline$\leq 5$ years & 23 & 46 & 20 & 44.44 & 3 & 60 \\
\hline 6 to 10 years & 24 & 48 & 23 & 51.11 & 1 & 20 \\
\hline$>10$ years & 3 & 6 & 2 & 4.44 & 1 & 20 \\
\hline Total & 50 & 100 & 45 & 100 & 5 & 100 \\
\hline
\end{tabular}

Table 5: Table showing the Distribution of Duration of Diabetes among Euthyroid and Hypothyroid Groups

\begin{tabular}{|c|c|c|}
\hline Duration of DM & Euthyroid & Hypothyroid \\
\hline N & 45 & 5 \\
\hline Mean & 6.00 & 7.60 \\
\hline SD & 2.08 & 3.71 \\
\hline P value Unpaired 't' test & \multicolumn{2}{|c|}{$0.03940563^{*}$} \\
\hline \multicolumn{2}{|c|}{ Table 6: Statistics of Duration of Diabetes among } \\
Study Population
\end{tabular}

By conventional criteria, the association between duration of diabetes and hypothyroidism is considered to be statistically significant since $\mathrm{p}<0.05$.

\section{Statistical Significance}

This indicates that there is a true difference among the study groups and the difference is significant.

In simple terms, while assessing the prevalence of hypothyroidism in diabetes mellitus, the average duration of 
diabetes mellitus is 6 years in euthyroid patients compared with 7.6 years in hypothyroid patients with a p-value of 0.03940563 according to Chi-Squared test.

\section{Clinical Significance}

The duration of diabetes mellitus is meaningfully less (26.66\%) in euthyroid compared to hypothyroid patients by a difference of 1 year and 7 months. Also the incidence of hypothyroid state in diabetic patients is much more in the first five years of diabetes mellitus (60\%). This difference is true and significant and has not occurred by chance.

So we conclude that there is an increased frequency of hypothyroidism early in duration of diabetes mellitus. This also proves that diabetes mellitus patients are at risk of developing hypothyroidism as a complication more in the first five years in our study.

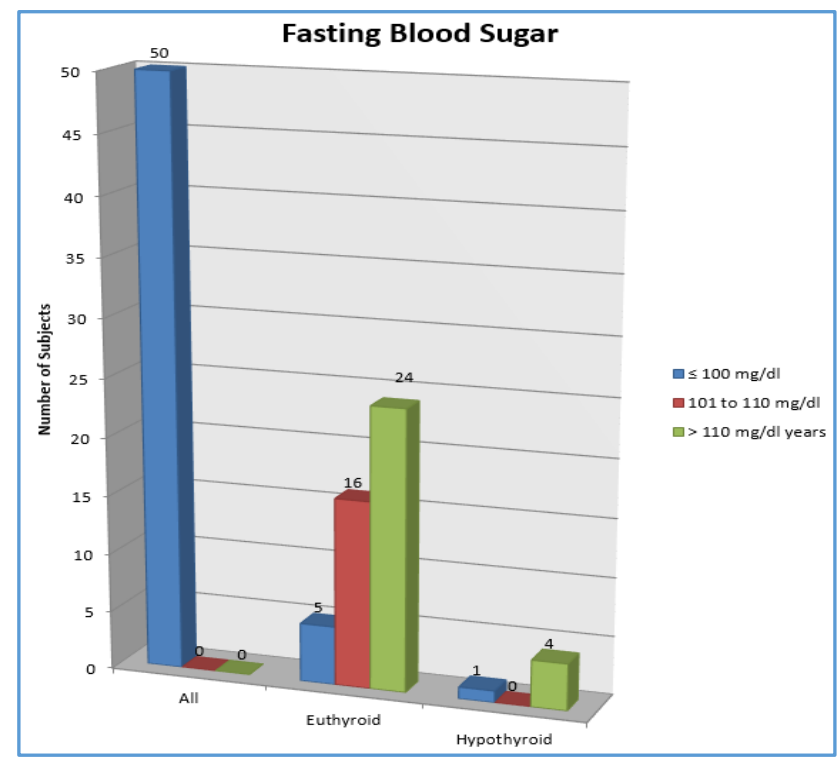

Fig. 4: Bar Diagram showing the Distribution of Fasting Blood Sugar Values among Study Population

\begin{tabular}{|c|c|c|c|c|c|c|}
\hline $\begin{array}{c}\text { Fasting Blood } \\
\text { Sugar }\end{array}$ & All & $\%$ & 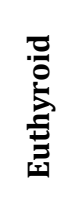 & $\%$ & 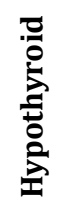 & $\%$ \\
\hline$\leq 100 \mathrm{mg} / \mathrm{dL}$ & 50 & 100 & 5 & 11.11 & 1 & 20 \\
\hline 101 to $110 \mathrm{mg} / \mathrm{dL}$ & 0 & 0 & 16 & 35.56 & 0 & 0 \\
\hline $\begin{array}{c}>110 \mathrm{mg} / \mathrm{dL} \\
\text { years }\end{array}$ & 0 & 0 & 24 & 53.33 & 4 & 80 \\
\hline Total & 50 & 100 & 45 & 100 & 5 & 100 \\
\hline \multicolumn{7}{|c|}{$\begin{array}{c}\text { Table 7: Table showing the Percentage Distribution of } \\
\text { Fasting Blood Sugar Values among Euthyroid and } \\
\text { Hypothyroid Groups }\end{array}$} \\
\hline
\end{tabular}

\begin{tabular}{|c|c|c|}
\hline Fasting Blood Sugar & Euthyroid & Hypothyroid \\
\hline N & 45 & 5 \\
\hline Mean & 111.98 & 119.00 \\
\hline SD & 8.91 & 13.08 \\
\hline P value & $0.008211^{*}$ \\
\hline Unpaired 't' test & \multicolumn{2}{|c|}{} \\
\hline $\begin{array}{c}\text { Table 8: Statistics of Fasting Blood Sugar Values among } \\
\text { Euthyroid and Hypothyroid Groups }\end{array}$ \\
\hline
\end{tabular}

By conventional criteria, the association between fasting blood sugar and hypothyroidism is considered to be statistically significant since $\mathrm{p}<0.05$.

\section{Statistical Significance}

This indicates that there is a true difference among the study groups and the difference is significant.

In simple terms, while assessing the prevalence of hypothyroidism in diabetes mellitus, the average fasting blood sugar is $111.98 \mathrm{mg} / \mathrm{dL}$ in euthyroid patients compared with $119 \mathrm{mg} / \mathrm{dL}$ in hypothyroid patients with a $\mathrm{p}$-value of 0.008211 according to Chi-Squared test.

\section{Clinical Significance}

The average fasting blood sugar is meaningfully less (6.27\%) in euthyroid patients compared to hypothyroid patients by a difference of $7.02 \mathrm{mg} / \mathrm{dl}$. This difference is true and significant and has not occurred by chance.

Sowe conclude that there is an increased frequency of higher fasting blood glucose in hypothyroid patients. This study shows that the hypothyroid condition will cause overall higher average fasting blood glucose than normal.

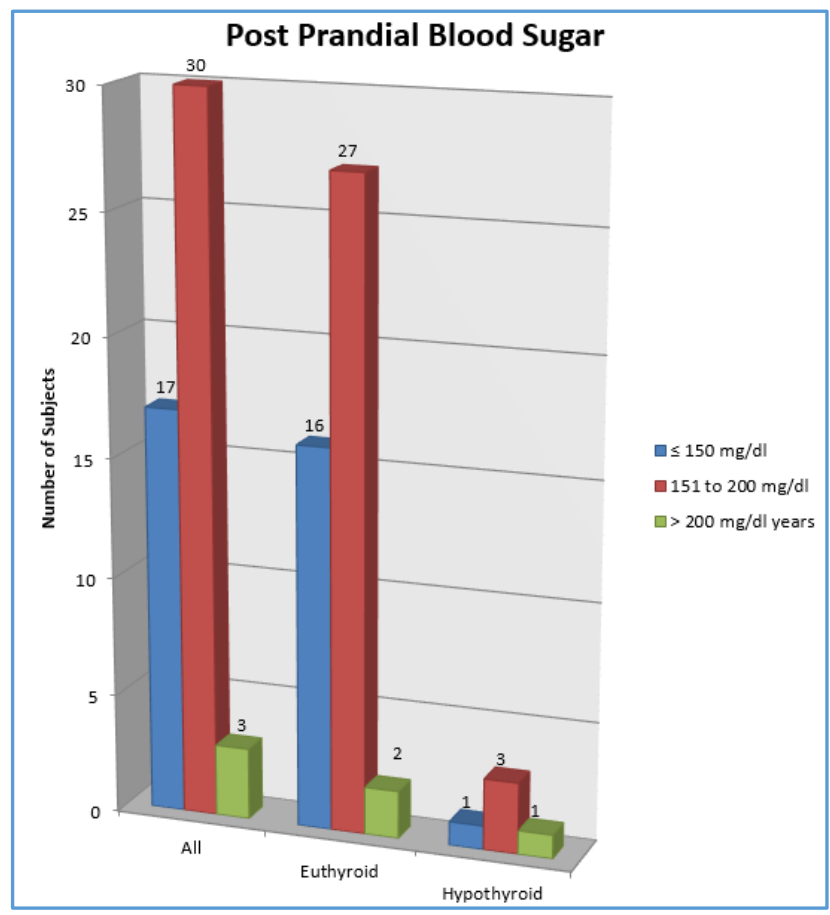

Fig. 5: Bar Diagram Representing the Distribution of PostPrandial Blood Sugar Values among Study Population

\begin{tabular}{|c|c|c|c|c|c|c|}
\hline $\begin{array}{l}\text { Post- } \\
\text { Prandial } \\
\text { Blood Sugar }\end{array}$ & All & $\%$ & : & $\%$ & 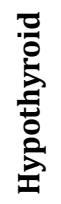 & $\%$ \\
\hline$\leq 150 \mathrm{mg} / \mathrm{dL}$ & 17 & 34 & 16 & 35.56 & 1 & 20 \\
\hline 151 to $200 \mathrm{mg} / \mathrm{dL}$ & 30 & 60 & 27 & 60.00 & 3 & 60 \\
\hline $\begin{array}{c}>200 \mathrm{mg} / \mathrm{dL} \\
\text { years }\end{array}$ & 3 & 6 & 2 & 4.44 & 1 & 20 \\
\hline Total & 50 & 100 & 45 & 100 & 5 & 100 \\
\hline \multicolumn{7}{|c|}{$\begin{array}{c}\text { Table 9: Table showing the Percentage Distribution of } \\
\text { Post-Prandial Blood Sugar Values among } \\
\text { Study Population }\end{array}$} \\
\hline
\end{tabular}




\begin{tabular}{|c|c|c|}
\hline Post-Prandial Blood Sugar & Euthyroid & Hypothyroid \\
\hline N & 45 & 5 \\
\hline Mean & 159.40 & 172.60 \\
\hline SD & 20.64 & 26.62 \\
\hline $\begin{array}{c}\text { P value } \\
\text { Unpaired 't' test }\end{array}$ & \multicolumn{2}{|c|}{0.3366892} \\
\hline $\begin{array}{c}\text { Table 10: Statistics of Post-Prandial Blood Sugar Values in } \\
\text { Euthyroid and Hypothyroid Groups }\end{array}$ \\
\hline
\end{tabular}

By conventional criteria, the association between the study groups and post-prandial is considered to be not statistically significant since $p>0.05$.

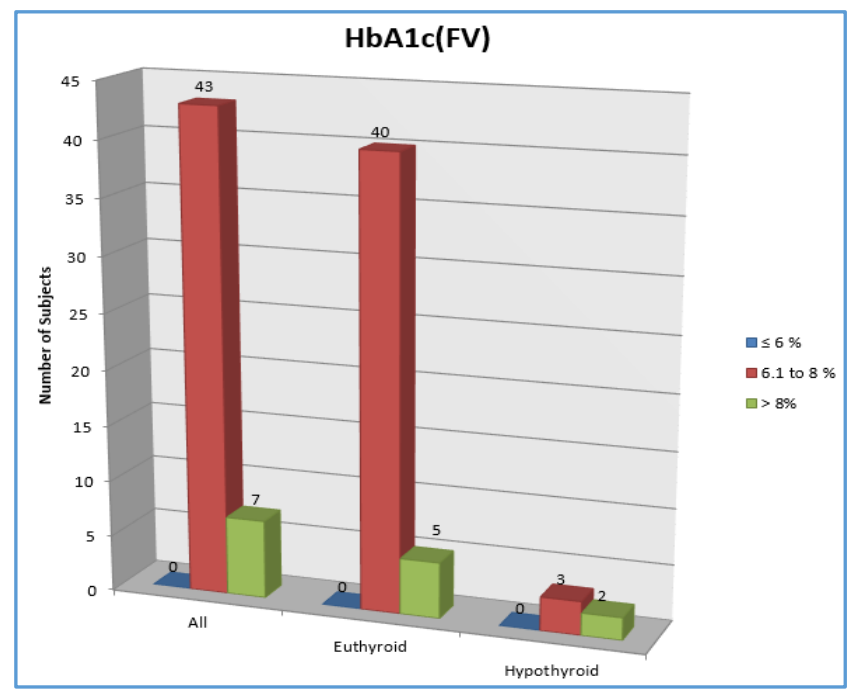

Fig. 6: Bar Diagram Representing the Distribution of HbA1c Values among the Study Population

\begin{tabular}{|c|c|c|c|c|c|c|}
\hline $\begin{array}{c}\text { HbA1c } \\
\text { (FV) }\end{array}$ & All & $\%$ & 尊 & $\%$ & 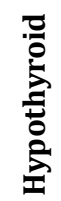 & $\%$ \\
\hline$\leq 6 \%$ & 0 & 0 & 0 & 0.00 & 0 & 0 \\
\hline 6.1 to $8 \%$ & 43 & 86 & 40 & 88.89 & 3 & 60 \\
\hline$>8 \%$ & 7 & 14 & 5 & 11.11 & 2 & 40 \\
\hline Total & 50 & 100 & 45 & 100 & 5 & 100 \\
\hline \multicolumn{7}{|c|}{$\begin{array}{c}\text { Table 11: Table showing the Percentage Distribution of } \\
\text { HbA1c Values among Euthyroid and } \\
\text { Hypothyroid Groups }\end{array}$} \\
\hline
\end{tabular}

\begin{tabular}{|c|c|c|}
\hline HbA1c (FV) & Euthyroid & Hypothyroid \\
\hline N & 45 & 5 \\
\hline Mean & 7.54 & 8.76 \\
\hline SD & 0.49 & 0.59 \\
\hline $\begin{array}{c}\text { P value } \\
\text { Unpaired 't' test }\end{array}$ & $0.0022491^{*}$ \\
\hline \multicolumn{2}{|c|}{ Table 12: Statistics of HbA1c Values in Euthyroid } \\
and Hypothyroid Groups \\
\hline
\end{tabular}

By conventional criteria, the association between $\mathrm{HbA1c}$ Fasting value and hypothyroidism is considered to be statistically significant since $\mathrm{p}<0.05$.

\section{Statistical Significance}

This indicates that there is a true difference among the study groups and the difference is significant. In simple terms while assessing the prevalence of hypothyroidism in diabetes mellitus, the average HbA1c-Fasting value is $7.54 \%$ in euthyroid patients compared with $8.76 \%$ in hypothyroid patients with a p-value of 0.0022491 according to Unpaired t-test.

\section{Clinical Significance}

The average HbA1c - Fasting value is meaningfully less (2.89\%) in euthyroid patients compared to hypothyroid patients by a difference of $1.22 \%$. This difference is true and significant and has not occurred by chance.

Hence, we conclude that there is an increased frequency of higher HbA1c - Fasting value in hypothyroid patients. This study shows that the hypothyroid condition will cause an overall higher average HbA1c - Fasting value than normal.

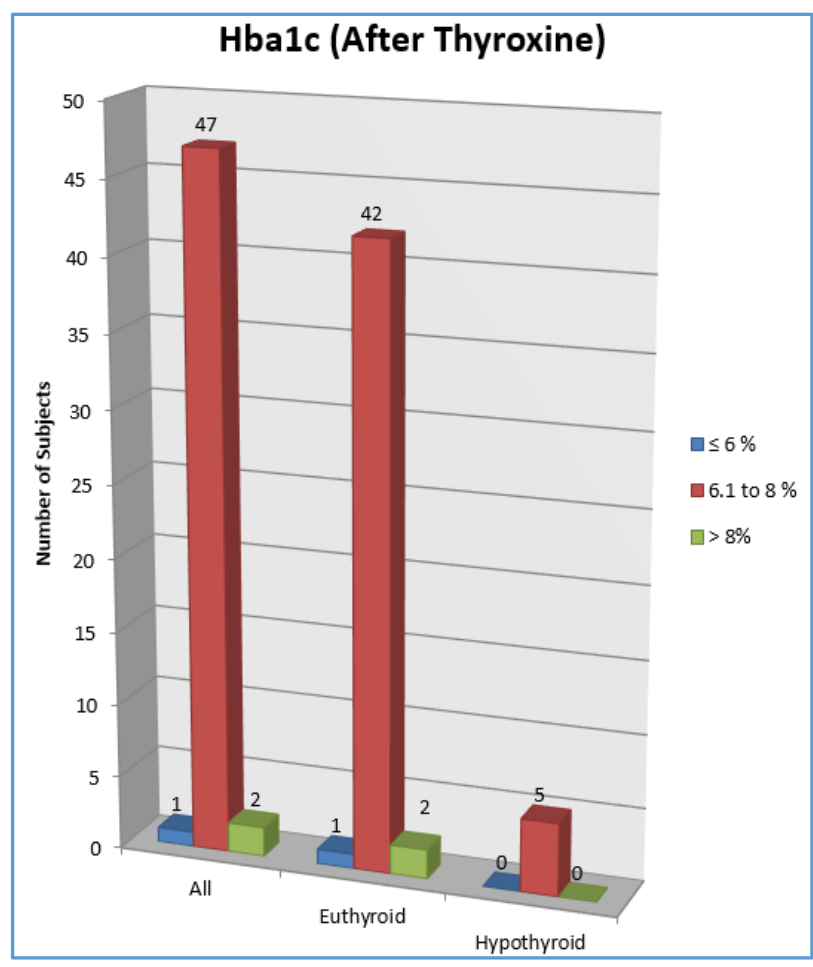

Fig. 7: Bar Diagram Representing the Distribution of HbA1c Values after Thyroxine Supplementation among the Study Population

\begin{tabular}{|c|c|c|c|c|c|c|}
\hline $\begin{array}{c}\text { HbA1c } \\
\text { (After } \\
\text { Thyroxine) }\end{array}$ & All & $\%$ & 尊 & $\%$ & 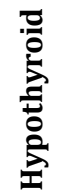 & $\%$ \\
\hline$\leq 6 \%$ & 1 & 2 & 1 & 2.22 & 0 & 0 \\
\hline 6.1 to $8 \%$ & 47 & 94 & 42 & 93.33 & 5 & 100 \\
\hline$>8 \%$ & 2 & 4 & 2 & 4.44 & 0 & 0 \\
\hline Total & 50 & 100 & 45 & 100 & 5 & 100 \\
\hline
\end{tabular}

\begin{tabular}{|c|c|c|}
\hline HbA1c (After Thyroxine) & Euthyroid & Hypothyroid \\
\hline N & 45 & 5 \\
\hline Mean & 7.18 & 7.24 \\
\hline SD & 0.42 & 0.62 \\
\hline $\begin{array}{c}\text { P value } \\
\text { Unpaired t test }\end{array}$ & \multicolumn{2}{|c|}{$033053^{*}$} \\
\hline \multicolumn{2}{|c|}{ Hable 14: Statistics of HbA1c values in Euthyroid and } \\
Hypothyroid groups \\
\hline
\end{tabular}


By conventional criteria the association between $\mathrm{HbA1c}$ After Thyroxine value and hypothyroidism is considered to be statistically significant since $p<0.05$.

\section{Statistical Significance}

This indicates that there is a true difference among the study groups and the difference is significant. In simple terms, while assessing the prevalence of hypothyroidism in diabetes mellitus, the average HbA1c-After Thyroxine value is $7.18 \%$ in euthyroid patients compared with $7.24 \%$ in hypothyroid patients with a p-value of 0.033053 according to Unpaired t- test.

\section{Clinical Significance}

The average HbA1c- after Thyroxine value is meaningfully less $(0.89 \%)$ in euthyroid patients compared to hypothyroid patients by a difference of $0.06 \%$. This difference is true and significant and has not occurred by chance.

Sowe conclude that there is a decreased frequency of higher HbA1c - after Thyroxine value in hypothyroid patients compared to HbA1c - Fasting values. This study shows that the corrected hypothyroid condition will cause a lower average HbA1c - after Thyroxine value very near to normal.

\begin{tabular}{|c|c|c|}
\hline $\begin{array}{l}\text { HbA1c } \\
\text { Levels }\end{array}$ & $\begin{array}{c}\text { Mean } \\
\text { (Euthyroid) }\end{array}$ & $\begin{array}{c}\text { Mean } \\
\text { (Hypothyroid) }\end{array}$ \\
\hline $\begin{array}{l}\text { HbA1c Fasting } \\
\text { Value }\end{array}$ & $7.54 \mathrm{mg} / \mathrm{dL}$ & $8.76 \mathrm{mg} / \mathrm{dL}$ \\
\hline $\begin{array}{l}\text { HbA1c After } \\
\text { Thyroxine } \\
\text { Value }\end{array}$ & $7.18 \mathrm{mg} / \mathrm{dL}$ & $7.24 \mathrm{mg} / \mathrm{dL}$ \\
\hline $\begin{array}{c}\text { P value } \\
\text { Paired t-test }\end{array}$ & $0.0000^{*}$ & $0.0138^{*}$ \\
\hline $\begin{array}{c}\text { Pearson } \\
\text { Correlation }\end{array}$ & 0.783429338 & 0.895299319 \\
\hline \multicolumn{3}{|c|}{$\begin{array}{c}\text { Table 15: Statistics of HbA1c values Before and After } \\
\text { Thyroxine Supplementation in Euthyroid and } \\
\text { Hypothyroid Groups }\end{array}$} \\
\hline
\end{tabular}

By conventional criteria, the association between HbA1cFasting and after Thyroxine values are considered to be statistically significant since $\mathrm{p}<0.05$.

The average HbA1c - After Thyroxine value is meaningfully less (21\%) in hypothyroid patients compared to HbA1c Fasting values by a difference of $1.52 \%$ with a $\mathrm{p}$-value of 0.0138 according to paired t-test. This difference is true and significant and has not occurred by chance.

There is a strong positive correlation between HbA1c Fasting and after Thyroxine values among hypothyroids in diabetes mellitus subjects in our study. This is indicated by the Pearson's R Correlation value of 0.895299319. The increase in HbA1c levels among diabetics correlates positively, directly and strongly with the increase in hypothyroid status. This means the hypothyroid status increases, as the $\mathrm{HbA1c}$ values increase.

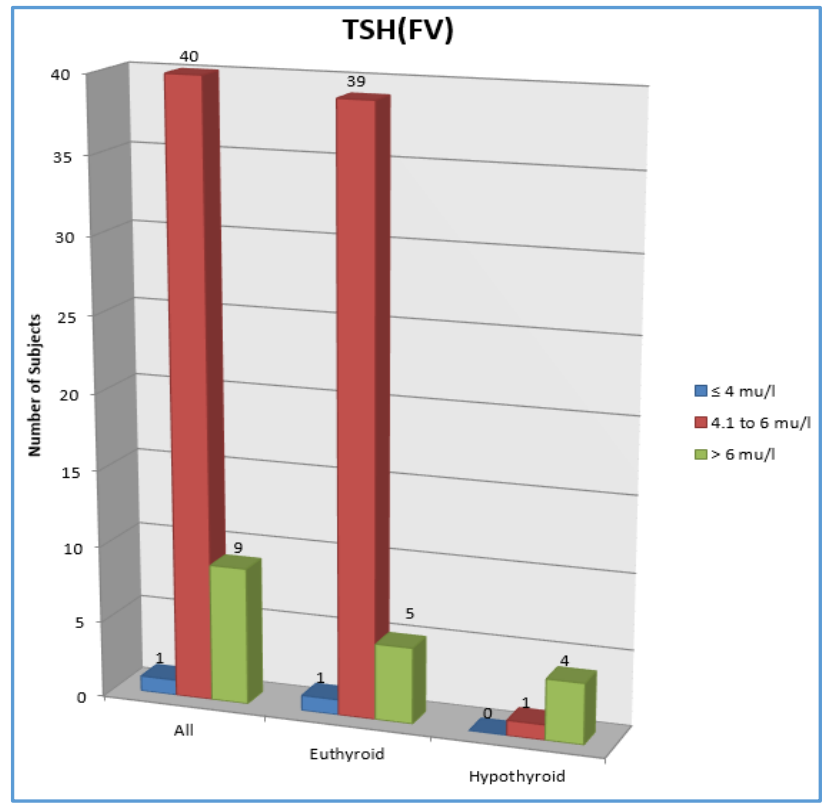

Fig. 8: Bar Diagram Representing the Distribution of TSH (Fasting Value) among the Study Population

\begin{tabular}{|c|c|c|c|c|c|c|}
\hline TSH (FV) & All & $\%$ & 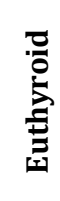 & $\%$ & 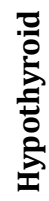 & $\%$ \\
\hline$\leq 4 \mathrm{mu} / \mathrm{L}$ & 1 & 2 & 1 & 2.22 & 0 & 0 \\
\hline 4.1 to $6 \mathrm{mu} / \mathrm{L}$ & 40 & 80 & 39 & 86.67 & 1 & 20 \\
\hline$>6 \mathrm{mu} / \mathrm{L}$ & 9 & 18 & 5 & 11.11 & 4 & 80 \\
\hline Total & 50 & 100 & 45 & 100 & 5 & 100 \\
\hline
\end{tabular}

\begin{tabular}{|c|c|c|}
\hline TSH (FV) & Euthyroid & Hypothyroid \\
\hline N & 45 & 5 \\
\hline Mean & 5.58 & 6.94 \\
\hline SD & 0.64 & 0.86 \\
\hline $\begin{array}{c}\text { P value } \\
\text { Unpaired ' } t \text { ' test }\end{array}$ & \multicolumn{2}{|c|}{$0.0222323^{*}$} \\
\hline Table 17: Statistics of TSH Values in Euthyroid and \\
Hypothyroid Groups \\
\hline
\end{tabular}

By conventional criteria, the association between TSHFasting value and hypothyroidism is considered to be statistically significant since $\mathrm{p}<0.05$.

\section{Statistical Significance}

This indicates that there is a true difference among the study groups and the difference is significant.

In simple terms while assessing the prevalence of hypothyroidism in diabetes mellitus, the average TSH-Fasting value is $5.58 \mathrm{mu} / \mathrm{L}$ in euthyroid patients compared with 6.94 $\mathrm{mu} / \mathrm{L}$ in hypothyroid patients with a p-value of 0.0222323 according to Unpaired t-test.

\section{Clinical Significance}

The average HbA1c - Fasting value is meaningfully less $(24.42 \%)$ in euthyroid patients compared to hypothyroid 
patients by a difference of $1.36 \mathrm{mu} / \mathrm{L}$. This difference is true and significant and has not occurred by chance.

Hence, we conclude that there is an increased frequency of higher TSH-Fasting value in hypothyroid patients. This study shows that the hypothyroid condition will cause an overall higher average TSH-Fasting value than normal.

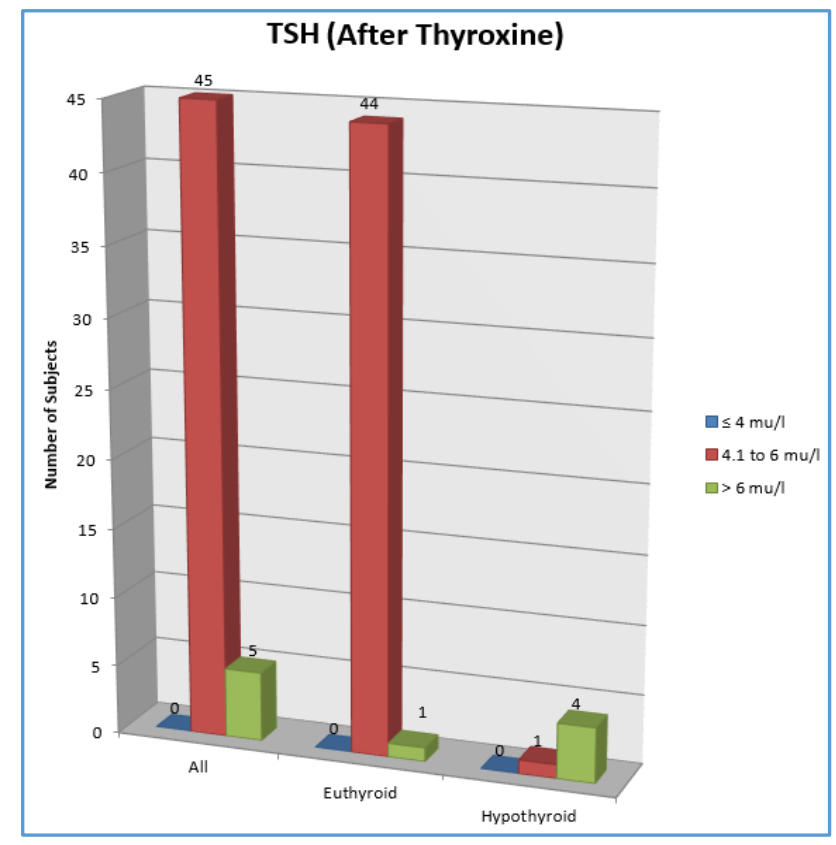

Fig. 9: Bar Diagram Representing the Distribution of TSH Values after Thyroxine Supplementation among Study Population

\begin{tabular}{|c|c|c|c|c|c|c|}
\hline $\begin{array}{c}\text { TSH } \\
\text { (After } \\
\text { Thyroxine) }\end{array}$ & All & $\%$ & 吾 & $\%$ & 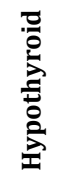 & $\%$ \\
\hline$\leq 4 \mathrm{mu} / \mathrm{L}$ & 0 & 0 & 0 & 0.00 & 0 & 0 \\
\hline $\begin{array}{c}4.1 \text { to } 6 \\
\mathrm{mu} / \mathrm{L}\end{array}$ & 45 & 90 & 44 & 97.78 & 1 & 20 \\
\hline$>6 \mathrm{mu} / \mathrm{L}$ & 5 & 10 & 1 & 2.22 & 4 & 80 \\
\hline Total & 50 & 100 & 45 & 100 & 5 & 100 \\
\hline \multicolumn{7}{|c|}{$\begin{array}{c}\text { Table 18: Table showing the Percentage Distribution of TSH } \\
\text { Values after Thyroxine Supplementation in Euthyroid and } \\
\text { Hypothyroid Groups }\end{array}$} \\
\hline
\end{tabular}

\begin{tabular}{|c|c|c|}
\hline TSH (After Thyroxine) & Euthyroid & Hypothyroid \\
\hline N & 45 & 5 \\
\hline Mean & 5.42 & 5.74 \\
\hline SD & 0.34 & 0.76 \\
\hline $\begin{array}{c}\text { P value } \\
\text { Unpaired 't' test }\end{array}$ & \multicolumn{2}{|c|}{$0.0173477^{*}$} \\
\hline $\begin{array}{c}\text { Table 19: Statistics of TSH Values after Thyroxine } \\
\text { Supplementation in Euthyroid and Hypothyroid Groups }\end{array}$ \\
\hline
\end{tabular}

By conventional criteria, the association between TSH after Thyroxine value and hypothyroidism is considered to be statistically significant since $\mathrm{p}<0.05$.

\section{Statistical Significance}

This indicates that there is a true difference among the study groups and the difference is significant.
In simple terms while assessing the prevalence of hypothyroidism in diabetes mellitus, the average TSH - after Thyroxine value is $5.42 \mathrm{mu} / \mathrm{L}$ in euthyroid patients compared with $5.74 \mathrm{mu} / \mathrm{L}$ in hypothyroid patients with a p-value of 0.0173477 according to Unpaired t-test.

\section{Clinical Significance}

The average TSH - after Thyroxine value is meaningfully less $(5.86 \%)$ in euthyroid patients compared to hypothyroid patients by a difference of $0.32 \mathrm{mu} / \mathrm{L}$. This difference is true and significant and has not occurred by chance.

So we conclude that there is a decreased frequency of higher TSH - after Thyroxine value in hypothyroid patients compared to TSH - Fasting values. This study shows that the corrected hypothyroid condition will cause a lower average TSH - after Thyroxine value very near to normal.

\begin{tabular}{|c|c|c|}
\hline TSH Levels & $\begin{array}{c}\text { Mean } \\
\text { (Euthyroid) }\end{array}$ & $\begin{array}{c}\text { Mean } \\
\text { (Hypothyroid) }\end{array}$ \\
\hline TSH Fasting Value & $5.58 \mathrm{mu} / \mathrm{L}$ & $6.94 \mathrm{mu} / \mathrm{L}$ \\
\hline $\begin{array}{c}\text { TSH After } \\
\text { Thyroxine Value }\end{array}$ & $5.42 \mathrm{mu} / \mathrm{L}$ & $5.74 \mathrm{mu} / \mathrm{L}$ \\
\hline $\begin{array}{c}\text { P value } \\
\text { Paired t-test }\end{array}$ & $0.03762^{*}$ & $0.01161^{*}$ \\
\hline $\begin{array}{c}\text { Pearson } \\
\text { Correlation }\end{array}$ & 0.129498659 & 0.969915853 \\
\hline
\end{tabular}

Table 20: Statistics of TSH values Before and After Thyroxine Supplementation in Euthyroid and Hypothyroid Groups

By conventional criteria, the association between TSH before and after Thyroxine values are considered to be statistically significant since $\mathrm{p}<0.05$.

The average TSH - after Thyroxine value is meaningfully less $(20.9 \%)$ in hypothyroid patients compared to TSH Fasting values by a difference of $1.2 \mathrm{mu} / \mathrm{L}$ with a p-value of 0.01161 according to Paired t-test. This difference is true and significant and has not occurred by chance.

There is a strong positive correlation between TSH Fasting and after Thyroxine values among hypothyroids in diabetes mellitus subjects in our study. This is indicated by the Pearson's R Correlation value of 0.969915853 . The increase in TSH levels among diabetics correlates positively, directly and strongly with the increase in hypothyroid status. This means as the hypothyroid status increases, the TSH values increase.

\section{DISCUSSION}

Diabetes Mellitus and Hypothyroidism are closely related endocrine disorders, and both are associated with several metabolic abnormalities.

The effect of thyroid hormones, T4 and T3, on body homeostatic energy and metabolic regulation is explained by its action on peripheral tissues. Secretion of insulin is influenced by thyroid hormone. Hypothyroidism causes decrease in glucose-related beta cell insulin secretion. Gene array studies in hypothyroid patient's skeletal muscle have shown a classical effect on sugar transporter expression by down-regulating the GLUT5 in hypothyroidism. On the contrary, expression of GLUT4 is not changed, but model animals showed altered translocation of GLUT4 to the cell membrane and negative alteration of enzyme-based degradation of intracellular sugar in hypothyroid state. The oxidation of glucose and synthesis of glycogen are reduced when there is decreased thyroid function. The sensitivity of insulin is documented to improve with rising thyroid 
hormone concentrations. This is dependent on production of T3 within the cells as polymorphisms of deiodinase with reduced generation of $\mathrm{T} 3$ have a close association with resistance of insulin in diabetic patients.

A positive association between insulin resistance and thyroxine is not only seen in diabetic patients, but also in people with normal glucose tolerance. Insulin resistance indices as evaluated by the homeostatic model assessment (HOMA, which judges before meal and post meal resistance of insulin) are related to normally functioning thyroid subjects, where HOMA is associated with an increase in thyroid concentrations normally. The normalization of TSH levels leads to a reduction in post-prandial glucose levels, CRP, HbA1c and lipids. This indicates that there is a positive correlation between thyroxine supplementation and glycaemic control in patients with subclinical hypothyroidism.

The interaction between thyroid status and metabolic control insists us the need for keen monitoring of thyroid function in type 2 diabetes mellitus patients. As proved through studies that there is increased prevalence of thyroid dysfunction in diabetes mellitus patients, it is necessary to put forth new recommendations for frequently investigating, the groups which are at greater risk like patients over 50 or 55 years of age, especially in presence of clinical suspicion and increased titres of antibody or lipid abnormalities on yearly or twice yearly basis. So it is necessary to suggest that an initial testing of TSH and TPO antibody will help us to analyse the development of hypothyroidism in patients with diabetes mellitus. Determination of TSH is accurate, accessible, safe and inexpensive test to diagnose hypothyroidism. Determining the level of TSH can be used to define the risk of the occurrence of various complications (Osteoporosis, cardiovascular disease, depression) for different intervals between TSH.

Subclinical hypothyroidism is quite hard to diagnose. In practice this is often overlooked. Adequate diagnosis requires conducting extensive laboratory tests other than routine TSH test. Keen monitoring of body temperature and clinical signs and a properly taken case history helps earlier and easier detection of this disease in medical practice.

This study concluded that the average HbA1c - Fasting value was found to be meaningfully less in euthyroid patients compared to that of hypothyroid patients by a difference of $1.22 \%$.

The study also concluded that the average HbA1c levels after thyroxine supplementation decreased when compared to the pre-treatment values. Henceforth, it is established that the proper correction of hypothyroid status in a diabetic individual helps us to achieve a better glycaemic control.

Leuwei et al(1) did a study at Capital Medical University in Beijing's Tongren Hospital to find out the effect of subclinical hypothyroidism on diabetes mellitus and on glucose metabolism. They found that in their study population, the hypothyroid patients with subclinical hypothyroidism had significant abnormalities in glucose metabolism like control of FBS, PPBS, HbA1c and they found significant positive correlation between the parameters. Our study showed similar positive correlation.

ZelejaVelija-Asimi et al(2) at University Clinical Centre, performed a trial to study the effects of subclinical hypothyroidism on metabolic control and hyperinsulinaemia. The study included 53 patients and they followed up the patients for 6 months after administering L-thyroxine. They found a better control of FBS, PPBS and HbA1c and fasting lipid profile. They found a positive correlation between HbA1c and TSH and positive correlation between HbA1c and insulin. Thus they concluded that normalised TSH levels will result in decreased levels of fasting insulin, FBS, PPBS and HbA1c Edina Bilic-Komarica et al(3) conducted a study to understand the effects of treatment of $\mathrm{L}$-thyroxine on glucose regulation in patients with subclinical hypothyroidism. The study group consisted of 100 patients, out of which 38 patients were diabetic. The patients were followed up after 6 months of L-thyroxine and physical activity and tests performed were T3, T4, TSH, HbA1c, CRP and insulin and lipid levels. After 6 months with the normalised TSH values FBS, PPBS, HbA1c, fasting insulin and lipids were significantly reduced thus concluding that normalising TSH levels with thyroxine treatment will control blood sugar better.

\section{CONCLUSIONS}

- There is a higher prevalence of hypothyroid state among the diabetic patients and this is more likely to happen in initial five years after diagnosis.

- The average fasting blood sugar values were higher among Hypothyroid patients with diabetes.

- There is a strong positive correlation between TSH and HbA1c values, both before and after thyroxine supplementation in patients with diabetes mellitus and concomitant hypothyroidism.

- Hence, this study concludes that treating concomitant hypothyroidism in patients with diabetes mellitus helps us to achieve a better control of blood sugar values.

\section{REFERENCES}

1. Wei L, Lin $H$, Xuelian $Z$, et al. The relationship between subclinical hypothyroidism and diabetic retinopathy in elderly type 2 diabetic patients [J]. Chinese Journal of Geriatrics 2014;33(11).

2. Velija-Asimi Z, Karamehic J. The effects of treatment of subclinical hypothyroidism on metabolic control and hyperinsulinaemia. Med Arh 2007;61(1):20-1.

3. Bilic-Komarica E, Beciragic A, Junuzovic D. Effects of treatment with L-thyroxin on glucose regulation in patients with subclinical hypothyroidism. Med Arch 2012;66(6):364-8. 